\title{
AN AFFECTIVE ROLE MODEL OF SOFTWARE AGENT FOR EFFECTIVE AGENT-BASED E-LEARNING BY INTERPLAYING BETWEEN EMOTIONS AND LEARNING
}

\author{
Shaikh Mostafa Al Masum, Mitsuru Ishizuka \\ Department of Information and Communication Engineering \\ Graduate School of Information Science and Technology, University of Tokyo \\ 7-3-1 Hongo, Bunkyo-ku, Tokyo, 113-8656, Japan \\ E-mail:mostafa@miv.t.u-tokyo.ac.jp, ishizuka@miv.t.u-tokyo.ac.jp
}

\begin{abstract}
Keywords: Affective Model for e-Learning, Emotion and e-Learning, Agent-based learning, Affective Computing, Elearning, Emotion Dynamics, Affective Pedagogy

Abstract: $\quad$ E-learning could become the major form of training and development in organizations as technologies will improve to create a fully interactive and humanized learning environment (Tim L. Wentling, et al, 2000). Hence to recognize this objective this paper would like to explain about an affective role model of a software agent to facilitate interactive online learning by considering and incorporating emotional features associated to learning with a view to strengthening the expectation of Lister (Lister, et al, 1999) that the differences between F-to-F and purely web-based courses are rapidly disappearing. The paper first presents the relationships between emotion and learning from different literatures and surveys. Then an affective model for e-learning is explored. After the model the paper enlists the emotion dynamics underpinned by a software agent. The paper concludes with the notion of future and extension of further research.
\end{abstract}

\section{INTRODUCTION}

With the augmentation and evolution of web technologies, e-learning is gaining popularity day by day. According to Michael (Michael M, 2002) webbased courses, are characterized by a predominance of asynchronous activities that replace the typical face-to-face (F-to-F) classroom interaction between the students, instructor and content. The differences between F-to-F and purely web-based courses are rapidly disappearing (Lister, et al, 1999) and this spawned yet another term called "blended learning" (Michael M, 2002). Hence we are very optimistic towards this blended nature of learning with the momentum and popularization of broadband internet facilities and effective conglomeration of Information Technology and human psychology. The following statistical information gives raise to this hope, at least.

- The e-learning industry is still booming and is expected to grow from $\$ 6.3$ billion in 2001 to more than $\$ 23$ billion in 2004 (International Data Corporation).
- At the end of April 2001, the MIT announced that, within a 10 year program, its almost 2000 courses will be put on-line, available for free access to everybody (Virginio, et al, 2004)

- $36 \%$ of US Universities have been considering or offering online courses and $14 \%$ have had a declared policy rewarding instructors for online course development. (Campus Computing Project, 2002).

- According to (Hall, 2000 and Tom, 2000) today, organizations are in synch with and using content providers, authoring tools, training management systems, portals, delivery systems and integrated solutions to foster their eLearning endeavours.

In the future, the term e-Learning may be obsolete because technology will appear invisible to both the learner and instructor because the technology-rich environment will fill the gap of the necessity of real class-room environment. Hence research on manifold issues is needed. One of the scopes could be that e-Learning technologies will allow for a humanized learning environment (Virginio, et al, 2004) and so this paper tends to characterize such humanized agent. 


\section{LEARNING AND EMOTION: ARE THEY INTERTWINED?}

There has been little exploration of the extent whether emotion is associated with learning online. Martin and Briggs (Martin, et al, 1986) almost twenty years ago now, proposed the integration of the two domains, affective and cognitive, into a more holistic and realistic framework for instructional design. The proposal was not popularized for the continuing separation of emotion and cognition with the difficulty in defining perspectives and a multitude of definitions of emotions (Frijda, 1994, James, 1952, Shweder, 1994). In this context let's figure out the definitions of emotion, affect, and cognition.

Emotion can be regarded as some combination (with various emphases and sequences) of physiological, psychological and psychomotor components. James (James, 1952) was an early promoter of this general approach, defining emotion in terms of the feeling of the 'bodily expressions' which follow the perception of an 'exciting fact'. Other variations identify 'affective' and 'somatic' dimensions of emotion (Shweder, 1994), 'experiential, behavioral and physiological' aspects (Frijda, 1994) or 'corporeal' and 'cognitive' dimensions (Worthman, 1999). However, a clear, agreed upon definition seems to be not easily arrived. As LeDoux (LeDoux, 1999 p.23) said "everyone knows what [emotion] is until they are asked to define it." To the question what are emotions, LeDoux responds "there are many answers and many of these are surprisingly unclear and ill-defined". The picture of emotions that emerges is diverse and multifaceted. This complexity makes the task of exploring the relationship between emotions and learning a difficult one, even though several attempts are obvious in (Kerry, 2003, LeDoux, 1999). Kerry conducted a survey with the online course- taking students. All the participants spoke of a range of emotions both positive and negative which had been associated with, and had impacted on, their learning.

Affect is influenced by or resulting from the emotions (Margaret, 1999). Affective includes aspects such as passion, frustration, satisfaction, distress, joy, fulfilment, gratitude, comfort, arrogance, or disinterest arguments that create a result.

Cognition can be defined as the mental process of knowing or acquiring to know. Cognition describes how people become aware of, gain, manage, and build new knowledge about the world. According to Margaret, a more pragmatic, comprehensive view of learning considers the differing influence and complex relationships between conative, affective, cognitive, social, and other relevant learning-related factors recognize dominant psychological factors, other than just cognitive aspects, that influence learning. McLeod's (McLeod, 1994) review of research into emotion and learning in mathematics identifies separate cognitive and affective domains. Shelton (Shelton, 2000), too, writing of the importance of emotion in learning addresses the need to develop certain 'emotional competencies' before learning can proceed satisfactorily. Similarly, Postle (Postle, 1993) describes of the importance of 'emotional competence' in relation to learning. In his terms, learning can be inhibited by emotional incompetence. So, with this approach, emotion is relevant to learning in that it provides a base or substrate out of which healthy cognitive functioning can occur. This has led to a growing awareness and researchers have started to admit that emotion and learning have inextricable juxtapositions. "Cognition is not as logical as it was once thought and emotions are not as illogical" (LeDoux, 1999). Stock (Stock, 1996) acknowledges that 'all sensory input is processed through our emotional centre first before it is sent to be processed in our rational mind'. The centrality of emotion in many cognitive processes is now being acknowledged.

As Goleman (Goleman, 1995) puts that the extent to which emotional upsets can interfere with mental life is no news to teachers. Students who are anxious, angry, or depressed don't learn; people who are caught in these states do not take in information efficiently or deal with it well." (Goleman, pp. 78). It is therefore imperative that the interaction with the "machine" be as "un-traumatic" as possible. In elearning, ignoring the emotional factors that come into play may lead to total failure (Virginio, 2004). The impact of emotions and intentions on learning, in the real world, are an integral part of learning and cannot be separated from learning and thinking ability, that is, we cannot consider one without considering the other (Margaret, 1999).

\section{AN AFFECTIVE MODEL FOR E- LEARNING}

The affective role involves the personal motivation and satisfaction of the learner. Affective behavior has a direct positive impact on cognitive learning (Duchastel, 1993). Lepper and Chabay (Lepper, et al, 1998) note that "motivational components of tutoring strategies are as important as cognitive components, and more generally, that truly personalized instruction must be individualized 
along motivational as well as cognitive dimensions" (p. 243). Duchastel similarly stresses the need for the affective role in the discussion of study guides for correspondence of courses. A number of roles played by instructors are identified by Coppola, et al, (Coppola, et al, 2001). According to them three particularly crucial ones are the cognitive, affective, and managerial roles. The cognitive role determines the actual interplay of learning/teaching. How we present content, provide interaction, and reinforce learning is the subject of this role. The affective role involves motivation and satisfaction.

Hence the useage of intelligent software agents, to simulate learning environments for teaching and learning process, can provide a way to function and simulate the "human" aspect of instruction in a more cost-effectively and interactive way than other controlled computer-based methods. Kort, et al, (Kort, et al, 2001) thus assume that computers will, much sooner than later, be more capable of recognizing human behaviors that lead to strong inferences about affective state of learner. Proposed model of Kort, et al, describes the range of various emotional states during learning. In this paper we depict our own model of affective behavior for elearning environment, which we define as Cubic Emotional Model (CEM) of e-learners.

We define e-learning as a synergetic action of Motivation (m), Lesson (l) and Assessment (a). These three also need some clarification. According to (Williams, 1997) we also admit motivation is a state of cognitive and emotional arousal which leads to a conscious decision to act, and gives rise to a period of sustained intellectual and/or physical state. Lesson means the real educational contents or the topic/subject matter to teach or to be taught. Assessment is actually the evaluation. The evaluation may be of pre-impression and/or ongoing impression and/or post-impression of the system of learning process (e.g. e-learning). Assessment actually answers the questions like "how about learning online?” or "Am I enjoying the lesson?” or "How was it?" or "Did I do well?" Form the literature (Angel, et al, 1998)(del Soldato, 1994),(Driscroll, 2000), (Edward, 1910) of educational psychology we can build the following dependencies.

- Motivation is proportional to Learning.

- Motivation is proportional to Assessment.

So we can conclude motivation is directly proportional to both learning and assessment. Hence we represent E-learners' Emotional Behavior (EEB) as the integration of motivation, lesson and assessment with respect to time spent with the computer for the lesson.

$$
\begin{aligned}
& \mathrm{EEB}=\int_{0}^{t}[m(t)+l(t)+a(t)] d t \ldots \ldots \ldots . .(1) \\
& \text { 3.1 Cubic Emotional Model (CEM) of } \\
& \text { Online Learners }
\end{aligned}
$$

\subsection{Cubic Emotional Model (CEM) of Online Learners}

The following CEM (Figure 1) represents 3dimensional state-model of emotional states of a student. We define eight emotional states at the very corners of the cube and at a particular time a student remain at a particular point in the 3-dimensional space of the cube which indicates a certain value of contentment (e.g. $\mathrm{H}^{\prime}$ ). As human mental states are complex one in nature, we cannot strictly describe the dynamics of mental states by simple equations. Student's motivation depends on his/her biological, environmental factors and so assessment, pace and fruitfulness of lesson varies differently over time. Thus we can imagine almost uncountable numbers of cubes (e.g. cube $\mathrm{AB}^{\prime} \mathrm{C}^{\prime} \mathrm{D}^{\prime} \mathrm{F}^{\prime} \mathrm{E}^{\prime} \mathrm{G}^{\prime} \mathrm{H}^{\prime}$ ), each might represent the mental state of a learner at a particular time, $t$, during learning.

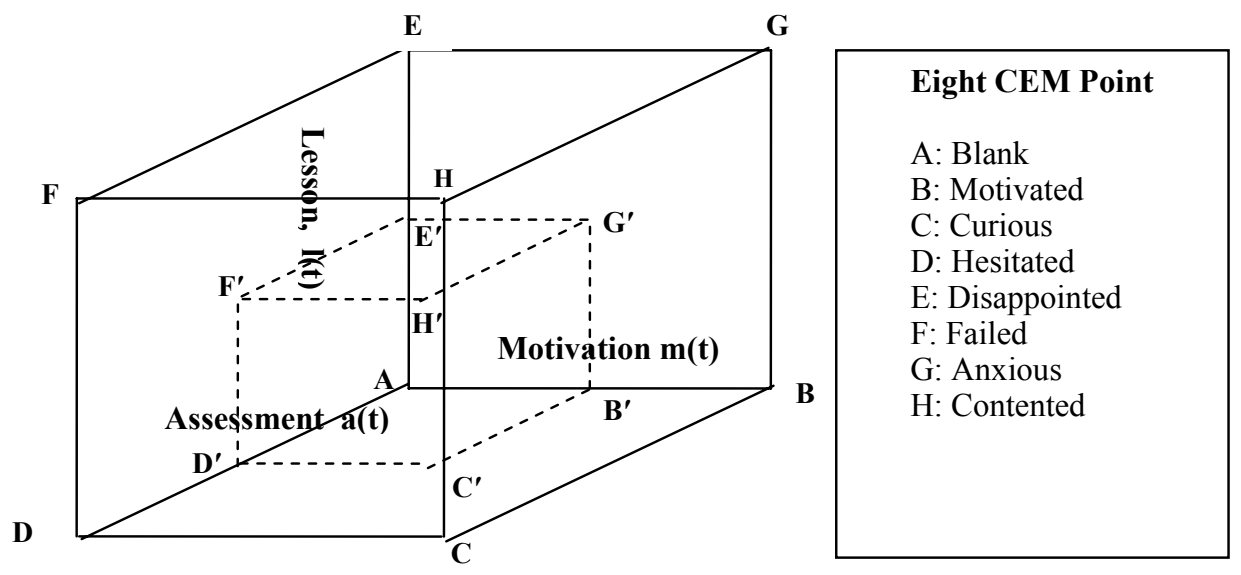

Figure 1: Cubic Emotional Model (CEM) 
So it will not be high-sounding if we say that at a particular time a student's emotional states varies between "Blank" to "Contented" states or in other way, literarily in a specific time, a student is certain amount of motivated or hesitated or disappointed but at the same time he might be anxious or curious or failed (bored), while all these give him a certain amount of contentment. Obviously this fuzziness of emotional state is needed to be simplified or regularized for a computer program (software agent) to behave accordingly. Such simplification in terms of emotion transitional rules will be jotted down in the next section.

The following table (table 1) is necessary to get a clear idea of the Eight CEM points. It indicates the eight emotional states along with corresponding emotional traits.

\subsection{Emotional States of Software Agent}

To correspond affectively with different affective states of e-learners we also figure out different roles, action and emotional characteristics of our software
Table 1: Affective Role Model of Software Agent

\begin{tabular}{|l|l|}
\hline \multicolumn{1}{|c|}{$\begin{array}{c}\text { Emotional } \\
\text { Sate }\end{array}$} & \multicolumn{1}{c|}{ Emotional Traits } \\
\hline Blank & $\begin{array}{l}\text { Desire, Uncertainty, Hope, } \\
\text { Imagination, Dull }\end{array}$ \\
\hline Motivated & $\begin{array}{l}\text { Interest, Comfort, Motivation, } \\
\text { Approaching, Encouragement }\end{array}$ \\
\hline Curious & $\begin{array}{l}\text { Thrill, Trusting, Anticipatory, } \\
\text { Expecting, Curiosity }\end{array}$ \\
\hline Hesitated & $\begin{array}{l}\text { Discomfort, Confusion, } \\
\text { Dissatisfaction, Hesitation }\end{array}$ \\
\hline Disappointed & $\begin{array}{l}\text { Shame, Embarrassment, } \\
\text { Pessimism, Worry, } \\
\text { Disappointment, Anger }\end{array}$ \\
\hline Failed & $\begin{array}{l}\text { Boredom, Tired, Exhausted, } \\
\text { Inattentive, Inactive, Drowsy, } \\
\text { Sad, Disgust }\end{array}$ \\
\hline Anxious & $\begin{array}{l}\text { Fear, Anxiety, Enthusiasm, } \\
\text { Excitement }\end{array}$ \\
\hline Contented & $\begin{array}{l}\text { Pride, Confidence, Calm, } \\
\text { Satisfaction, lively, Happy, } \\
\text { Contentment }\end{array}$ \\
\hline
\end{tabular}

agent. Table 2 enlists the agent's affective role model. The 'Role' indicates the personality of the agent; Action indicates the basic tasks that the agent needs to perform or ponder to elicit the corresponding 'Characteristics'.

Table 2: Affective Role Model of Software Agent

\begin{tabular}{|l|l|l|l|}
\hline \multirow{2}{*}{$\begin{array}{c}\text { e-learners' CEM } \\
\text { Points }\end{array}$} & \multicolumn{3}{|c|}{ Software Agent's Affective Role Model } \\
\cline { 2 - 4 } & Role & Action & Characteristics \\
\hline Blank & Promoter & Promotion & Friendly, Elaborative, Hopeful, Welcoming \\
\hline Motivated & Parental & Stimulation & Encouraging, Wishful, Approaching \\
\hline Curious & Pedagogue & Lesson/Teach & $\begin{array}{l}\text { Informative, Pedagogy, Loving, Polite, Calm, } \\
\text { Rationale }\end{array}$ \\
\hline Hesitated & Advisor/Counselor & Motivation & Cheering, Confident, Enthusiastic, Caring \\
\hline Disappointed & Buddy & Inspiration & $\begin{array}{l}\text { Amicable, Cordial, Inspiring, Optimistic, } \\
\text { Approving, Agreeable }\end{array}$ \\
\hline Failed & Entertainer & Amusement & Energetic, Flexible, Jocund, Funny, Animated \\
\hline Anxious & Coordinator & Explanation & Eloquent, Skillful, Agile, Helpful, Expressive \\
\hline Contented & Admirer & Praise & Excited, Proud, Happy, Suggestive, Satisfied \\
\hline
\end{tabular}

\subsection{Transition of Emotional State of e- learners and Behavior Semantic of Software Agent}

Koda \& Maes (Koda, et al, 1996) suggest that more expressive agents have greater motivational impact. However, Dietz \& Lang (Dietz, et al, 1999) found that while users preferred agents showing more emotion and performed better on a memorization task with the emotion-showing agents, the results were not statistically significant. One of the first suggestions of endowing computer tutors with a degree of empathy was made by Lepper and Chabay (Lepper, et al, 1998). They argued that motivational components are as important as cognitive components in tutoring strategies and those important benefits would arise from considering techniques to create computer tutors that have an ability to empathize. So we formulate Emotion State Transition (EST) of the software agent for the expected behavior of the agent towards the student with appropriate affects.

Following we mention role and action pair of software agent which we call the expected behavior 
of the agent corresponding to learns' emotional state. The main goal of the agent's interaction is to provide affects to lead the learners' emotional state to 'Contented' state.
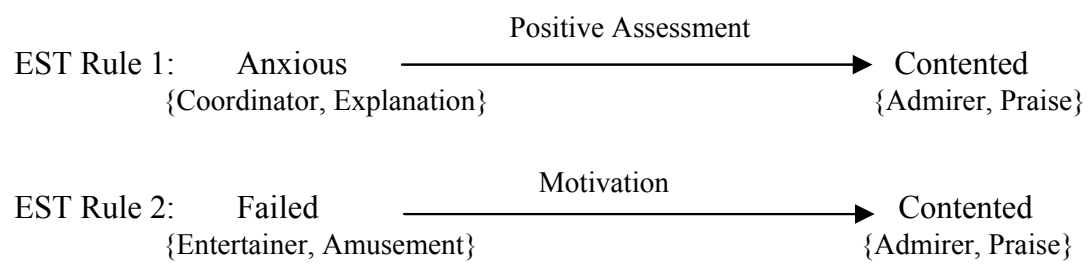

$\begin{array}{lll}\text { EST Rule 3: } & \begin{array}{l}\text { Curious } \\ \text { \{Pedagogue, Teach }\end{array} & \text { Cesson } \\ & \text { Contented } \\ \text { \{Admirer, Praise }\end{array}$

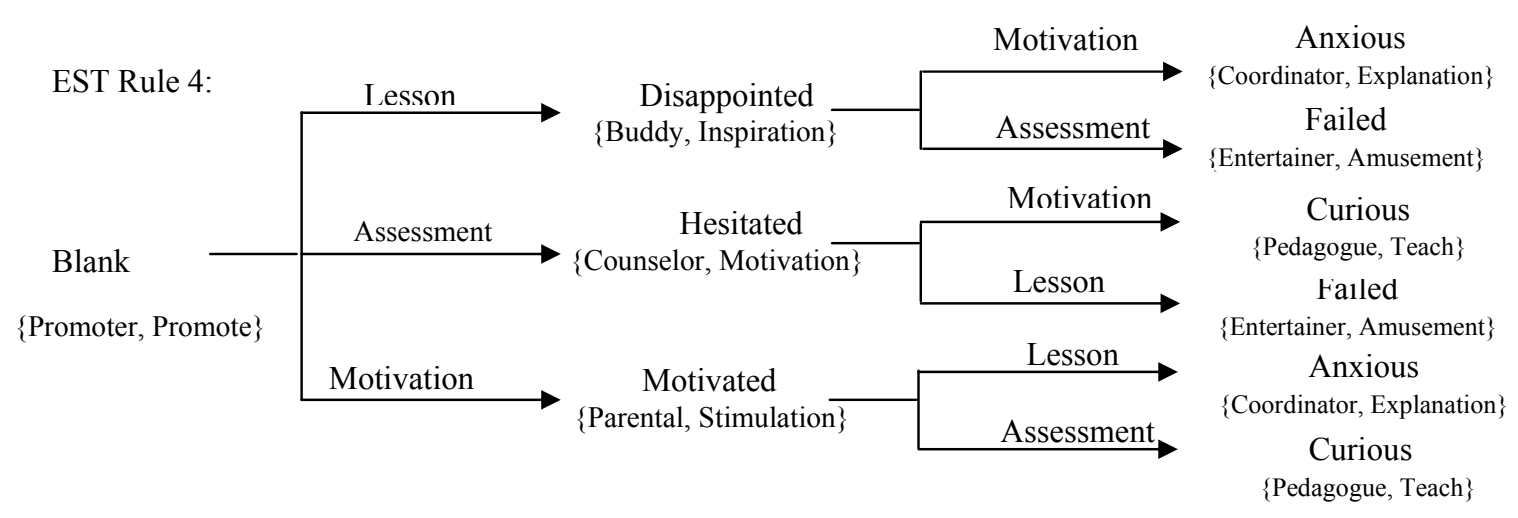

At the end of each state in EST Rule 4, any of the rules from 1 to 3 applies to lead a student "Contented" state.

For example, a learner's emotional state is blank at the outset, at that time the software agent behaves as a promoter to promote the course by friendly and welcoming attitude. Then the learner might feel 'Motivated' or 'Hesitated' or 'Disappointed' and depending upon the emotional state of the learner the agent will behave the student with corresponding affects. If the student is Motivated (for example) the agent will have parental behaviors to stimulate the learner for lesson or to develop an assessment. If the student is motivated to take lesson the agent then teaches the lesson with pedant like affect and during the lesson the learner might be anxious for the progress or any other reasons, then the agent takes the role of coordinator to explain the subject matter to grow positive assessment towards the student. If the student seems to be tired or inattentive or doing badly in test, indicating this as failure, the agent will try to provide amusement in terms of funny animation or story unfolding (depending on the type of student) to cheer up the student. So whatever the emotional state a learner is in, at a particular time, the agent has its corresponding role to play and behave to lead the student to 'Contented' state. But the sensing of the learner's emotional state or emotion (could be identified by physiological and other phenomena) is not in the scope of this paper. In fact there are lots of research is been done and still being done to sense human affects by capturing and processing various signals of human body (e.g. ECG, BP, RP, Skin Conductance etc.)

\section{BEHAVIORAL DYNAMICS OF SOFTWARE AGENT}

Before designing the behavioral dynamics of the agent we would like to describe the emotionality or affective characteristics of the software agent by several functional outputs. We imagine that our agent, for this time being at least, has the following emotional functions that provide some values 
(Prendinger,2001) as a functional output to render its personality with respect to different roles (e.g. counselor etc.)

a. Friendliness: This emotion value indicates how much friendly the agent will be. The parameters considered to define friendliness are: Companionability, Amity, Benevolence, Cordiality, Kindness and Agreeableness. So what does Friendliness (Agent, Student) mean? To us this indicates a functional value that gives a measure indicating the friendliness factor of the agent. While designing the function the aforementioned parameters are used and values of parameters get assigned according to Student's profile (e.g. demography, culture etc.). For example like in (Prendinger,2001) we assume intensities of friendliness, $f \in\{1, \ldots$. , 5 \}, which indicates the fuzzy values like not friendly (Strict), friendly but less cordial, friendly and cordial, friendly but less agreeable, friendly and agreeable(flexible) respectively.

b. Expressiveness: This emotion value indicates how much explainable the agent will be. The parameters considered are: Explanatory, Witty, Eloquence, Distinct, Articulateness and Coherent.

c. Encouragement: This emotion value indicates how much encourage-worthy the agent will be. The parameters considered are: Help, Support, Assistance, Inspiration

d. Parental: This emotion value indicates how much parents like the agent will act. The parameters considered are: Motherly, Fatherly, Sympathetic, Kindness, Strict

e. Optimism: This emotion value indicates how much optimistic the agent will be appeared. The parameters considered are: Calmness, Hopeful, Sureness, Positivism

f. Pedagogy: This emotion value indicates how much teacher-like the agent will act. The parameters considered are: Enlightened, Knowledgeable, Informative, Scientific, Learning

g. Loving: This emotion value indicates how much passionate the agent will express himself. The parameters considered are: Adoring, Affectionate, Committed, Attached, Anxious

h. Politeness: This emotion value indicates how polite the agent will be in terms of etiquette. The parameters considered are: Courteous, Mannerly, Cordial, Flattering, Respectful

i. Rationale: This emotion value indicates how much logical and analytical the agent will be in terms of Speech and Action. The parameters considered are: Logical, Reasonable, Inquisitive, Induced

j. Confidence: This emotion value indicates the level of confidence of the agent. The parameters considered are: Trust, Faith, Self-Assurance and Impulsiveness.

k. Animated: This emotion value indicates how much excitement the agent will render. The parameters considered are: Lively, Gall, Active, Cheerful and Brisk.

1. Funny: This emotion value indicates how much funny the agent will act. The parameters considered are: Humorous, Comic, Laughable and Whimsical.

m. Agility: This emotion value indicates how much prompt and alert the agent will be. The parameters considered are: Alertness, Cleverness, Promptitude and Quickness.

n. Happiness: This emotion value indicates how much happiness the agent might express. The parameters considered are: Satisfaction, Cheer, Enthusiasm and Contentment.

o. Recommending: This emotion value indicates how much suggestive or recommending the agent will be. The parameters considered are: Suggesting, Advising, Complementing and Admonishing.

This approach has the advantage of being relatively simple to implement, but since most of the emotional message seems to be non-verbal, it may prove to be too restricted for diagnosing student's motivation and it may be very difficult to elicit motivation diagnosis knowledge for this type of 'communication channel'. del Soldato performed a preliminary study to test the accuracy of her motivational modeler, but no conclusive results were obtained. The detail design of aforementioned functions of the above affective characteristics of the agent is not kept in the scope of the paper. Following we would like to enlist the Behavioral Dynamics (BD) of our agent using the above functional affective characteristics.

$<$ Role, Action $>$ : \{Promoter, Promotion\} $\mathrm{BD} 1(\mathrm{~A}, \mathrm{~S})=$ Friendliness $(\mathrm{A}, \mathrm{S}) \wedge$ Elaboration $(\mathrm{T}, \mathrm{S})$

$<$ Role, Action $>$ : $\{$ Parental, Stimulation $\}$ $\mathrm{BD} 2(\mathrm{~A}, \mathrm{~S})=$ Encouragement $(\mathrm{A}) \wedge$ Parental $(\mathrm{T}, \mathrm{S}) \wedge$ Optimism (A, S)

$<$ Role, Action $>$ : $\{$ Pedagogue, Teach $\}$

BD3(A,S) = Elaboration $(\mathrm{T}, \mathrm{S}) \wedge$ Pedagogy $(\mathrm{A}, \mathrm{S}) \wedge$ Loving $(\mathrm{A}, \mathrm{S}) \wedge$ Politeness $(\mathrm{A}, \mathrm{S}) \wedge$ Rationale $(\mathrm{A}, \mathrm{S})$ 
$<$ Role, Action $>$ : \{Advisor/Counselor, Motivation BD4 $(\mathrm{A}, \mathrm{S})=$ Encouragement $(\mathrm{A}) \wedge$ Confidence $(\mathrm{A}$, $\mathrm{T}) \wedge$ Loving $(\mathrm{A}, \mathrm{S}) \wedge$ Politeness $(\mathrm{A}, \mathrm{S}) \wedge$ Rationale $(\mathrm{A}, \mathrm{S})$

$<$ Role, Action $>$ : $\{$ Buddy, Inspiration $\}$ BD5 $(\mathrm{A}, \mathrm{S})=$ Friendliness $(\mathrm{A}, \mathrm{S}) \wedge$ Encouragement (A) $\wedge$ Optimism $(\mathrm{A}, \mathrm{S}) \wedge$ Loving $(\mathrm{A}, \mathrm{S})$.

$\leq$ Role, Action $>$ : $\{$ Entertainer, Amusement BD6 $(A, S)=$ Friendliness $(A, S) \wedge$ Animated $(A, S)$ $\wedge$ Funny $(\mathrm{A}, \mathrm{S})$.

$\leq$ Role, Action $>$ : $\{$ Coordinator, Explanation\} BD7 $(\mathrm{A}, \mathrm{S})=$ Elaboration $(\mathrm{T}, \mathrm{S}) \wedge$ Friendliness $(\mathrm{A}$ S) $\wedge$ Agility $(A) \wedge$ Pedagogy $(A, S)$

$\leq$ Role, Action $>$ : $\{$ Admirer, Praise $\}$ BD8 (A, S) $=$ Animated (A, S) $\wedge$ Happiness (A) $\wedge$ Recommending $(\mathrm{A}) \wedge$ Optimism $(\mathrm{A}, \mathrm{S})$...

For example the output of relation 1 may characterize the agent, with respect to Student (S) the Agent (A), needs to be friendly but less agreeable and Highly Elaborative for the Topic $\mathrm{T}$ and at the same time the role and action of the agent for relation 1 make the agent obliged to behave hopeful and welcoming (by uttering some pre-stored natural text, for example).

\section{CONCLUSION}

For enhancing quality and improving accessibility to education and training the use of e-learning is generally seen as one of the keystones for building the knowledge society, In Europe, in particular. It is indubitable that for an effective learning experience the learners are required to think deeply, as shallow thinking may lead only to shallow learning (Duchastel, 2004). Because e-learning has an instructor, students, and a computer, LaRose and Whiten (LaRose, et al, 2000) proposed that instructional immediacy in this context is comprised of three corresponding variables: computer immediacy, student immediacy, and teacher immediacy. Computer immediacy refers to the closeness that develops between learner and computer in the course of e-learning; the need for computer immediacy is also supported by Reeves and Nass (Reeves, et al, 1996), who advocate giving media personality by incorporating the same conventions of etiquette, which characterize human conversation. Student immediacy describes the behaviors that create a feeling of closeness between learners in an educational setting. Finally, teacher immediacy refers to "teaching behaviors that enhance closeness to and nonverbal interaction with another" (LaRose, 2000). The efforts described here focus on all the three immediacies. In the future work we would like to build the agent underpinned the aforementioned behavioral dynamics and program the agent by Multimodal Presentation Markup Language (MPML) (Tsutsui, et al, 2000) that supports affective tagging of agent. The proposed agent will express affect according to behavioral dynamics and render its action corresponding to roles by uttering different patterns of pre-stored texts and animation to communicate positive affect to the learners.

\section{REFERENCES}

Angel de V., \& Helen P., 1998. "Motivation Diagnosis in Intelligent Tutoring Systems", Intelligent Tutoring Systems: 4th International Conference, ITS '98, San Antonio, Texas, USA. Proceedings, Volume 1452 / 1998, p 86-95

Commission of the European Communities, "eLearning: designing tomorrow's education”, Interim Report (as requested by the Council Resolution of 13 July 2001), http://www.dapp.min-edu.pt/docs/eLearning Report Jan2002.html.

Coppola, N. W., Hiltz, S. R., \& Rotter, N., 2001. "Becoming a virtual professor: Pedagogical roles and $A L N$ ". Paper presented at the Hawaii International Conference on System Sciences 34, Maui, Hawaii.

del Soldato, T., 1994. "Motivation in tutoring systems", Tech. Rep. CSRP 303, School of Cognitive and Computing Sciences, The University of Sussex, UK.

Dietz, R. B., \& Lang, A., 1999. "Affective agents: Effects of agent affect on arousal, attention, liking and learning", Paper presented at the International Cognitive Technology Conference '99, San Francisco, CA

Driscoll, M. P., 2000. Psychology of learning for instruction (2nd ed.). Needham Heights, MA: Allyn and Bacon.

Duchastel, P., 1993. "Toward the ideal study guide", British Journal of Educational Technology, 14(3), 216220, Retrieved December 4, 2004, from http://www.globaldistancelearning.com/Teaching/Deli very/txt-02.html

Edward L. Thorndike, 1910. "The contribution of psychology to education", first published in The Journal of Educational Psychology, 1, 5-12. http://psychclassics.yorku.ca/Thorndike/education.htm

Frijda, N., 1994. "Emotions are functional, most of the time”, In: Ekman, P., \& Davidson, R. (Eds.), 
TheNature of Emotion: Fundamental Questions, Oxford University Press, New York/ Oxford, 112-122.

Goleman, D., 1996. "Emotional intelligence: Why it can matter more than IQ", Boomsbury, London, 1996. First published by Bantam Books, New York

Hall, B., 2000. "New study seeks to benchmark enterprises with world-class e-learning in place”, E-learning, 1 (1) 18 - 29.Urdan, T. A., and Weggen C. C.

James, W., 1952. "The Principles of Psychology", Encyclopedia Britannica, Chicago, 1891/1952.

Kerry O'Regan, 2003. "Emotion And E-Learning”, Journal of Asynchronous Learning Networks, JALN Volume 7, Issue 3, September 2003

Koda, T., \& Maes, P., 1996. "Agents with face: the effects of personification of agents", Paper presented at the HCI '96, London, UK

Kort, B., Reilly, R., Picard, R., 2001. "An Affective Model of Interplay Between Emotions and Learning: Reengineering Educational Pedagogy-Building a Learning Companion", International Conference on Advanced Learning Technologies, ICALT-2001, Madison, USA

LaRose, R. \& Whitten, P., 2000. "Re-thinking instructional immediacy for Web courses: A social cognitive exploration”, Communication Education, 49(4), 320-338

LeDoux, J., 1999. “The Emotional Brain: The Mysterious Underpinnings of Emotional Life", Phoenix, London

Lepper, M. R., \& Cabray, R. W., 1998. "Socializing the intelligent tutor: Bringing empathy to computer tutors”, In Mandl and Lesgold (Eds.), Learning issues for intelligent tutoring systems (pp. 247-257). New York: Springer-Verlag

Lister, B.C., Danchak, M.M., 1999. Scalzo, K.A., Jennings, C.W., Wilson, J., "The Rensselaer 80/20 Model for Interactive Distance Learning", EDUCAUSE '99, Long Beach, CA

Margaret M., 1999. "Intentional Learning in an Intentional World: Audience Analysis and Instructional System Design for Successful Learning and Performance", Proceedings of the 17th annual international conference on Computer documentation, New Orleans, Louisiana, United States, Pages: $211-220$

Martin, B. \& Briggs, L., 1986. "The Affective and Cognitive Domains: Integration for Instruction and Research", Educational Technology Publications, Englewood Cliffs

McLeod, D., 1994. "Research on affect and Mathematics learning in the JRME: 1970 to the present", Journal for Research in Mathematics Education, Vol. 25, No. 6, pp 637-647

Michael M. Danchak, 2002. "Bringing Affective Behavior to e-Learning", The Technology Source, September/October 2002. Available online at http://ts.mivu.org/default.asp?show $=$ article \&id $=962$

Postle, G., 1993. "Putting the heart back into learning", In: Boud, D., Cohen, R. \& Walker, D. (Eds.), Using
Experience for Learning, SRHE \& Open University Press, Buckingham, 33-45.

Prendinger, H., and Ishizuka, M., 2001. "Communicative Behavior of Socially Situated Agents”, Workshop Proc. on Multimodal Communication and Context in Embodied Agents (C. Pelachaud and I. Poggi (Eds.)), in conj. with Agents-01, pp.41--46, Montreal, Canada

Reeves, B. \& Nass, C., 1996. "The media equation", Stanford, MA: Cambridge University Press

Rodriguez, J. I., Plax, T. G., \& Kearney, P., 1996. "Clarifying the relationship between teacher nonverbal immediacy and student cognitive learning: Affective learning as the central causal mediator", Communication Education, 45, 293-305

Shelton, C., 2000. "Portraits in emotional awareness", Educational Leadership, pp 330 -32, September

Shweder, R., 1994. "“you're not sick, you're just in love': Emotion as an interpretative system", In: Ekman, P. \& Davidson, R. (Eds.), The Nature of Emotion: Fundamental Questions, Oxford University Press, New York/ Oxford, 32-44

Stock, B., 1996. "Getting to the heart of performance", Performance Improvement, Vol. 35, No. 8, pp 6-13

The Campus Computing Project (2002), "The 2002 National Survey of Information Technology in US Higher Education", Encino, CA: The Campus Computing Project

Tim L. Wentling, Consuelo W., 2000. Danielle S., Jennie F., Jason La Fleur, Alaina K., "The Future of eLearning: A Corporate and an Academic Perspective”, Knowledge and Learning Systems Group University Of Illinois At Urbana-Champaign, September 2000, Supported by Allstate Insurance Company Sears, Roebuck and Company \& Eastman Kodak Company

Tom B., 2000. "The future of digital learning”, E-learning May/June 2000, Vol. 1, No.2, pp. 46-7

Tsutsui, T., Saeyor, S., and Ishizuka, M., 2000. "MPML: A Multimodal Presentation Markup Language with Character Agent Control Functions”, Proc.(CD-ROM) WebNet 2000 World Conf. on the WWW and Internet, San Antonio, Texas, USA, (2000.10.30-2000.11.4)

Virginio C., Massimo C., Marco P., 2004. "Perspectives and challenges in e-learning: towards natural interaction paradigms", Journal of Visual Languages and Computing, 15 (2004) 333-345

Williams, M. and Burden, R. L., 1997. "Psychology for language teachers: A social constructivist approach", Cambridge University Press, Cambridge, UK

Worthman, C., 1999. "Emotions: You can feel the difference”, In: Hinton, A. Bio-cultural Approaches to the Emotions, Cambridge University Press, Cambridge, 41-74 